\title{
Winners of Christmas competitions
}

\section{Crossword answers}

\begin{tabular}{|c|c|c|c|c|c|c|c|c|c|c|c|c|c|}
\hline & $\mathbf{E}$ & $\mathbf{N}$ & & & & & & & & & & & \\
\hline & & 1 & & & & & & & I & & & & \\
\hline & $\mathbf{E}$ & C & & & & & $\underline{\mathbf{N}}$ & $\bar{U}$ & $\mathbf{R}$ & & & & $\mathbf{E}$ \\
\hline & & $\mathbf{E}$ & & & & & & & $\mathbf{E}$ & & & & \\
\hline & A & \begin{tabular}{l|l}
$\mathbf{R}$ & $\mathbf{1}$ \\
\end{tabular} & $\mathbf{E}$ & I & & & \begin{tabular}{l|l}
$\mathrm{H}$ & $\mathbf{E}$
\end{tabular} & & $\mathbf{E}$ & L & & C & T \\
\hline & $\mathrm{C}$ & & & & & & & & & & R & & $\mathbf{N}$ \\
\hline & - & $\mathbf{N}$ & $\mathbf{A}$ & & & & & & $\mathbf{R}$ & $I$ & & T & E \\
\hline & & & -7 & & & & $\mathbf{G}$ & & & $\mathbf{A}$ & & & 1 \\
\hline & A & $\mathbf{N}$ & I & & & & L & & $\mathbf{E}$ & $\mathbf{N}$ & & $\mathbf{s}$ & \\
\hline & & $\mathrm{U}$ & & & & & $\bar{U}$ & & $\mathrm{~L}$ & & & $\mathbf{E}$ & \\
\hline & $\mathrm{U}$ & $\mathbf{R}$ & $\mathrm{T}$ & 5 & & C & $\mathbf{O M}$ & $\mathbf{M}$ & $\mathrm{U}$ & $\mathbf{N}$ & & 1 & $\underline{Y}$ \\
\hline & & 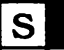 & & I & & & & & D & & & & E \\
\hline & A & I & $\mathbf{L}$ & & $A$ & $\mathbf{R}$ & A & & & $\mathbf{N}$ & & & A \\
\hline & & $\mathbf{N}$ & & c & & & $\mathbf{N}$ & & & & & & \\
\hline & $\mathbf{N}$ & $\mathbf{G}$ & & & & & & & & & & & \\
\hline
\end{tabular}

Congratulations to Dr M. Salzmann of Farnham. Surrey, who was the crossword winner.

\section{Quiz answers}

1. Recent novels with a psychiatric theme.

2. Fregoli - the impressionist immortalised in Fregoli's syndrome.

3. The Association of Medical Officers for Asylums and Hospitals for the Insane (which finally transmuted into the Royal College).

4. James Coburn in the film of that name.

5. DubStar in the 1995 hit single.

6. Richard Gere - he played a patient in one film and $a$ therapist in the other.

7. Thomas Szasz.

8. Private Secretary to the Prime Minister. He was shot by M'Naughten (or McNaughton).

9. Timothy Willocks - two of his novels.

10. Marlon Brando in the film of that name.

11. A cigarette in a cigarette holder in the painting by Magritte.

12. The neuroses in the classification of Adolf Meyer. 